\title{
The chemokine CXCL13 in acute neuroborreliosis
}

\author{
Makbule Senel, ${ }^{1}$ Tobias A Rupprecht, ${ }^{2}$ Hayrettin Tumani, ${ }^{1}$ Hans W Pfister, ${ }^{2}$ \\ Albert C Ludolph, ${ }^{1}$ Johannes Brettschneider ${ }^{1}$
}

${ }^{1}$ Department of Neurology, University of Ulm, Ulm, Germany ${ }^{2}$ Department of Neurology, Ludwig-Maximilians-University of Munich-Grosshadern, Munich, Germany

\section{Correspondence to}

Dr Hayrettin Tumani,

Department of Neurology, University of Ulm, Oberer Eselsberg 45, Ulm 89081 Germany;

hayrettin.tumani@uni-ulm.de

Received 18 September 2009 Accepted 20 November 2009

Published Online First

3 December 2009

\section{ABSTRACT}

Objective Recent studies have suggested an important role of the B cell chemoattractant CXCL13 in acute neuroborreliosis (NB). Our aim was to confirm the diagnostic role of CXCL13 and to evaluate its relevance as a therapy response and disease activity marker in NB. Methods CXCL13 was measured in cerebrospinal fluid (CSF) and serum of patients with NB $(n=28)$, systemic borreliosis (SB, $n=9$ ), Guillain-Barré syndrome (GBS, $n=11)$, Bell's palsy (BP, $n=19)$, other cranial nerve palsies (CNP, $n=5)$, cephalgia $(C, n=20)$, bacterial CNS infections (B-CNS-I, $n=16$ ) and viral CNS infections (VCNS-I, $n=18)$. For follow-up studies, serial sample pairs were evaluated from 25 patients with NB $(n=56), 11$ with B-CNS-I $(n=25)$ and 14 with V-CNS-I $(n=36)$.

Results CSF-CXCL13 was significantly elevated in NB compared with other neurological diseases $(p<0.001)$. Using receiver operating characteristic analysis, $337 \mathrm{ng} / \mathrm{g}$ was determined as a cut-off with a sensitivity of $96.4 \%$ and a specificity of $96.9 \%$. Of all the parameters investigated, CSF CXCL13 showed the fastest response to antibiotic therapy, decreasing significantly $(p=0.008)$ within 1 week. In untreated patients, CSF CXCL13 was elevated in patients with a short duration of disease. Borrelia burgdorferi antibody index showed no significant $(p=0.356)$ change over follow-up.

Conclusions The study confirms the relevance of CXCL13 as a diagnostic biomarker of NB and suggests that CSF CXCL13 in NB is linked to duration of disease and could be a marker of disease activity and response to antibiotic therapy.

\section{INTRODUCTION}

Neuroborreliosis (NB) is a nervous system manifestation of Lyme borreliosis, caused by the tickborne spirochete Borrelia burgdorferi (BB) ${ }^{1-4}$ Due to a great variety of neurological symptoms such as meningitis, meningoradiculitis or cranial nerve palsies, ${ }^{5} 6$ identification of neuroborreliosis frequently is a diagnostic challenge in clinical neurology. Currently the method of choice for the diagnosis of acute NB is the combined analysis of basic cerebrospinal fluid (CSF) parameters (lymphocytic pleocytosis, intrathecal synthesis of immunoglobulins and/or blood-CSF barrier dysfunction) and determination of BB-specific antibody index (BB-AI $\geq 1.5$, ie, intrathecal antibody synthesis to $\mathrm{BB}) .^{7}$ However, this approach has important limitations. First, elevated basic CSF variables are also found in various other inflammatory diseases of the central nervous system (CNS). ${ }^{8} 9$ Second, intrathecal $\mathrm{BB}$ antibody synthesis may not be detectable in early stages of disease, especially if the disease duration is less than 2-3 weeks. $^{10-14}$ Third, elevated BB-AI does not discriminate between active and past infections, as it is known to persist for years in spite of successful treatment. ${ }^{14}$ Fourth, false-positive results may occur due to antibody cross-reactivities. ${ }^{10} \quad \begin{array}{ll}15 & 16\end{array}$ Fifth, due to the use of different isolates as antigen in various immunosorbent assays for BB antibodies, results may vary considerably among different laboratories.

Recent studies have suggested an important role of CXCL13 in the diagnosis of NB. ${ }^{17} 18$ CXCL13 belongs to the CXC chemokine family and is a selective chemoattractant for B lymphocytes and B-helper $\mathrm{T}$ cells via the chemokine receptor CXCR5. ${ }^{19}$ Our aim was to confirm the diagnostic value of CXCL13 in NB in comparison with established diagnostic parameters such as BB-AI and to evaluate the relevance of CXCL13 as a marker of disease activity and therapy response in acute NB.

\section{METHODS \\ Patients}

Drawing of blood and lumbar puncture was performed for diagnostic purposes after the patient's informed consent was obtained. Paired CSF and serum samples were collected between January 2000 and September 2008 from 126 patients admitted to the Department of Neurology, University of Ulm, Germany (for demographic data, see table 1). Patients included 28 patients with definite neuroborreliosis (NB), according to criteria by Kaiser, ${ }^{7}$ and nine patients with systemic borreliosis (SB) who showed no clinical signs of neuroborreliosis and showed normal basic CSF findings (including cell count, total protein and lactate). At the time of lumbar puncture, none of the $\mathrm{NB}$ patients received any antibiotic therapy. Furthermore, we included 69 patients with neurological diseases relevant in the differential diagnosis of $\mathrm{NB}$, comprising 16 patients with bacterial infections of the CNS (B-CNS-D, including meningitis or meningoencephalitis caused by Treponema pallidum, Mycobacterium tuberculosis, Streptococcus pneumoniae, Meningococcus, Listeria monocytogenes, Haemophilus influenzae, Staphylococcus aureus or other Streptococci), 18 patients with viral CNS diseases (V-CNS$\mathrm{D}$, including meningitis or meningoencephalitis caused by herpes simplex virus (HSV), varicella zoster virus(VZV), Epstein-Barr virus(EBV), rubella virus, tickborne encephalitis virus(TBEV), enterovirus), 11 patients with Guillain-Barré syndrome (GBS), 19 patients with Bell's palsy (BP) and five patients with other cranial nerve palsies (CNP). As normal controls, we included 20 patients with cephalgia (C) who presented with tension-type headache and showed no evidence of a structural, haemorrhagic or inflammatory lesion. 
Table 1 Demographic data and basic cerebrospinal fluid findings of patients included in this study

\begin{tabular}{|c|c|c|c|c|c|c|}
\hline & n (female/male) & Age (years) & Cell count $(/ \mu \mathrm{l})$ & $\begin{array}{l}\text { Cerebrospinal fluid/serum } \\
\text { albumin concentration } \\
\text { ratio }\left(\times 10^{-3}\right)\end{array}$ & $\begin{array}{l}\text { Intrathecal } \lg M \\
\text { synthesis }(\%)\end{array}$ & $\begin{array}{l}\text { Oligoclonal IgG } \\
\text { bands }(\%)\end{array}$ \\
\hline Neuroborreliosis & $28(9 / 19)$ & 58 (32 to 70$)$ & 84 (50 to 187$)$ & 13.8 (9.7 to 23.3 ) & 78.6 & 85.7 \\
\hline $\begin{array}{l}\text { Bacterial infections of the central nervous } \\
\text { system }\end{array}$ & $16(9 / 7)$ & 53 (36 to 69$)$ & 2134 (117 to 4682$)$ & 58.1 (35.5 to 90.2$)$ & 18.8 & 13.3 \\
\hline $\begin{array}{l}\text { Viral infections of the central nervous } \\
\text { system }\end{array}$ & $18(3 / 15)$ & 38 (27 to 63$)$ & 178 (54 to 290$)$ & $11.8(8.8$ to 16.7$)$ & 16.7 & 22.2 \\
\hline Guillain-Barré syndrome & $11(4 / 7)$ & 40 (27 to 51$)$ & $1(0$ to 2$)$ & 17.4 (6.8 to 23.2$)$ & 9.1 & 63.6 \\
\hline Cranial nerve palsies & $5(1 / 4)$ & 65 (54 to 66$)$ & 2 (1 to 2$)$ & 6.2 (5.7 to 8.4$)$ & 0 & 0 \\
\hline Bell's palsy & $19(11 / 8)$ & 40 (26 to 67$)$ & 2 (1 to 3$)$ & $5.2(4.4$ to 6.0$)$ & 0 & 15.8 \\
\hline
\end{tabular}

Data are shown as the median and IQR.

For follow-up studies, we included serial CSF/serum sample pairs from 25 patients with $\mathrm{NB}(\mathrm{n}=56), 11$ patients with bacterial $(n=25)$ and 14 patients with viral $(n=36)$ infections of the CNS. Samples of eight of these NB patients were obtained from the Department of Neurology, Ludwig-Maximilians University, Munich, Germany. Standard antibiotic therapy of $\mathrm{NB}$ patients consisted of ceftriaxone $2 \mathrm{~g}$ intravenously per day over 2 weeks.

\section{CSF analysis and CXCL13 assay}

All CSF samples were stored at $-80^{\circ} \mathrm{C}$ until analysis. CSF leucocyte count (cells $/ \mathrm{mm}^{3}$ ), total protein $(\mathrm{g} / \mathrm{l})$, lactate ( $\mathrm{mmol} /$ 1), CSF/serum albumin concentration ratio $\left(\mathrm{Q}_{\mathrm{alb}}\right)$, immunoglobulin (Ig) G, A and M and oligoclonal IgG bands (OCB) were obtained as previously described. ${ }^{20}$ Intrathecal synthesis of antibodies to $\mathrm{BB}$ was determined by calculation of the specific antibody indices (AI): $\mathrm{AI}=\mathrm{OIg}[$ spec]/OIg[total], if $\mathrm{OIg}[$ total] < Olim, and AI=OIg[spec]/Olim, if OIg[total] $>$ Olim. ${ }^{21}$ The upper reference range of $\mathrm{OIg}$ [total], Olim, was calculated according to Reiber's formula. AI values $\geq 1.5$ were considered to be indicative of intrathecal Ig synthesis against $\mathrm{BB}^{21}$

CXCL13 was measured by quantitative enzyme-linked immunosorbent assay (ELISA) (Quantikine; R\&D Systems, Minneapolis, Minnesota) according to the instructions supplied by the manufacturer. For validating and assessing assay accuracy, spike-and-recovery as well as linearity-of-dilution experiments were performed. To compensate for differences in CSF protein due to blood-CSF barrier dysfunction in acute NB, CSF CXCL13 was related to total CSF protein in accordance with Rupprecht et al. ${ }^{17}$ The Borrelia afzelii+VIsE IgG ELISA (PKo strain, Genzyme Virotech, Rüsselsheim, Germany) was used for detection of IgG antibodies against BB sensu lato.

\section{Statistical analysis}

Statistical analysis was performed using SPSS (version 16.0; SPSS, Chicago, Illinois). Differences in CXCL13 between groups were analysed using Kruskal-Wallis test followed by single pairwise comparisons (Mann-Whitney $U$ test). Wilcoxon signed rank test was applied to compare concentrations at individual time points with baseline (diagnostic LP) values, and the Friedman test (repeated measures of ANOVA on ranks) was applied to analyse repeated values for a global analysis of progression. The correlation was analysed using the Spearman rank order correlation. To test for normality, the Kolmogorov-Smirnov test was applied. Sensitivity was calculated as (true-positive/(true-positive+false-negative)), specificity was calculated as (true-negative/(true-negative+false-positive)). To examine the accuracy of CXCL13 to differentiate NB from controls, we used a receiver operating characteristic (ROC) analysis, calculating the area under the ROC curve (AUROCC). The Youden index was calculated for each cut-off value as corresponding ((sensitivity+specificity)-1) to find the cut-off
Figure $1 \mathrm{CXCL13}$ (ng/g protein) in the cerebrospinal fluid (CSF) of neuroborreliosis and other neurological diseases; horizontal solid lines indicate medians. Kruskal-Wallis test and pairwise comparisons (Mann-Whitney $\mathrm{U}$ test) revealed a significant difference between the groups $(p<0.001)$. The dashed line at $337 \mathrm{ng} / \mathrm{g}$ represents the cut-off level yielding the highest combined sensitivity and specificity for discriminating patients with NB from those with other diseases. A grey triangle indicates an outlier (neurosyphilis patient) with cerebrospinal fluid CXCL13 of $113000 \mathrm{ng} / \mathrm{g}$. The $\mathrm{y}$-axis is broken twice. B-CNS-D, bacterial CNS disease; BP, Bell's palsy; C, cephalgia; CNP, cranial nerve palsies; GBS,

Guillain-Barré syndrome; NB, definite neuroborreliosis; $\mathrm{SB}$, systemic borreliosis; V-CNS-D, viral CNS disease.

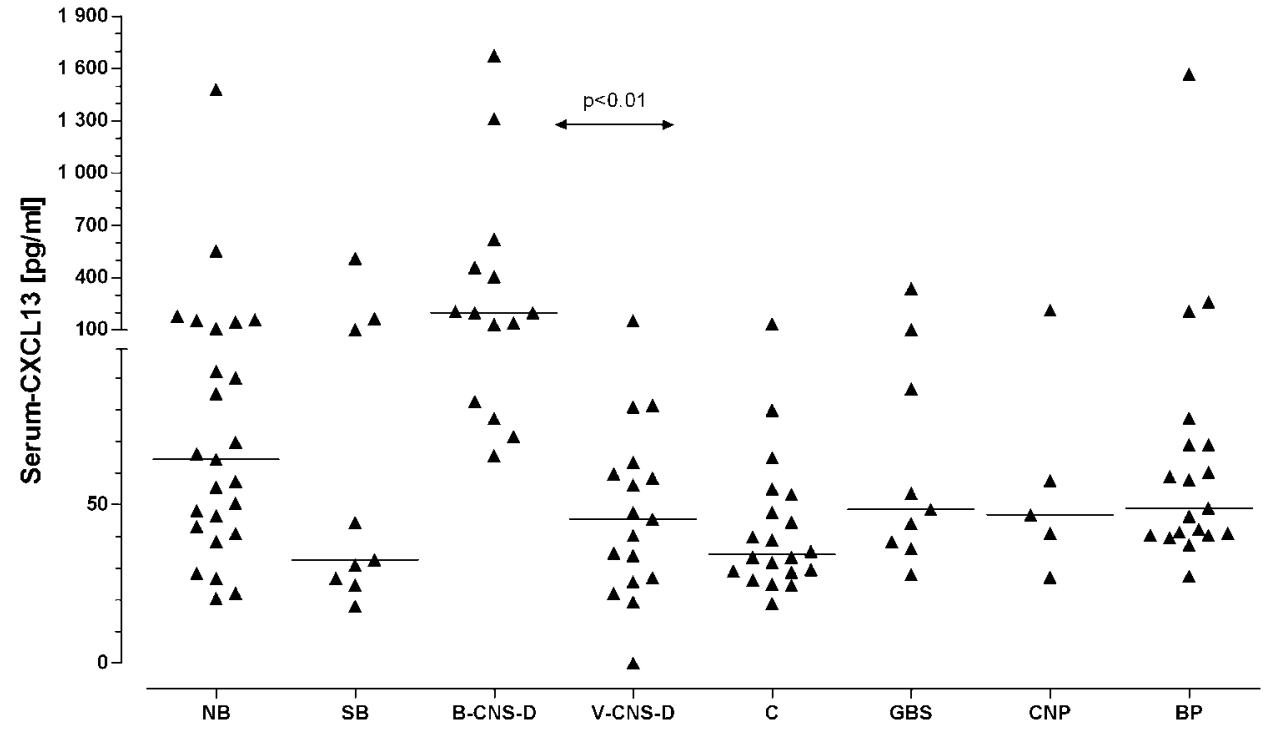


Figure 2 Cerebrospinal fluid CXCL13 in neuroborreliosis patients prior to therapy plotted against time since the onset of symptoms (time to lumbar puncture). The straight line is a regression line; the correlation was significant ( $p=0.044, R=-0.383$ ).

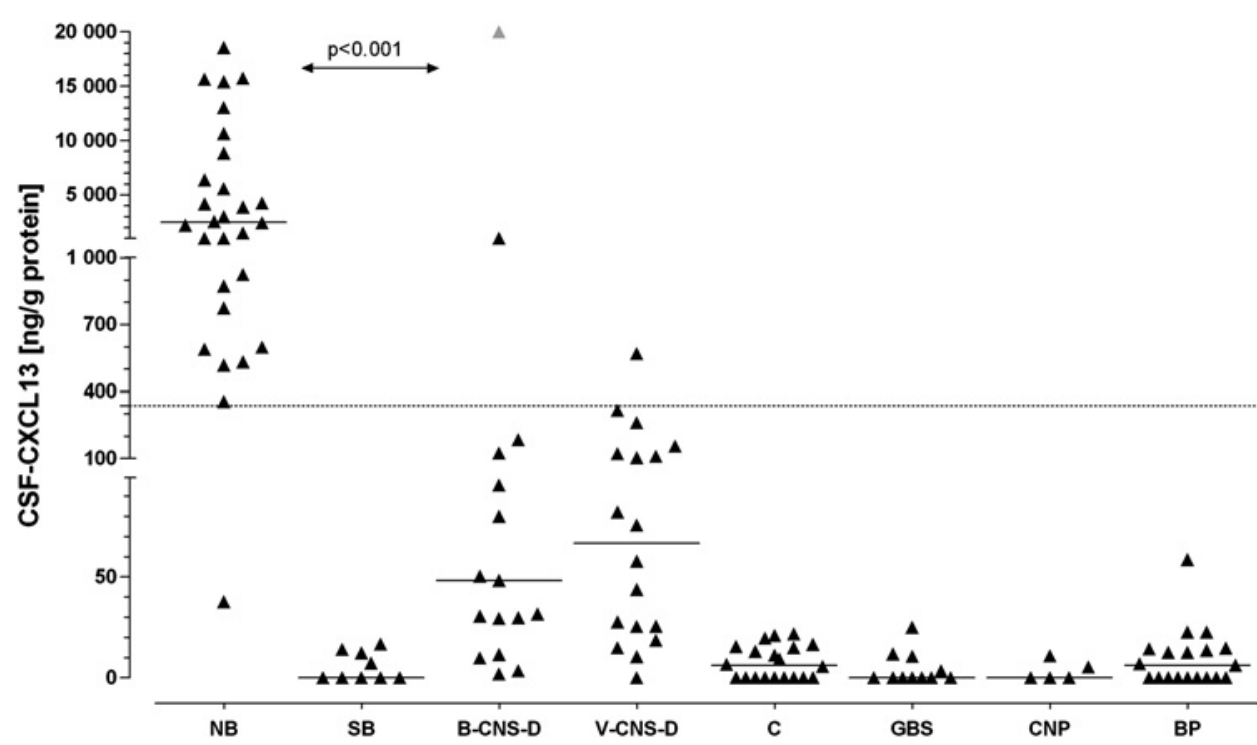

values which maximise discriminating accuracy. ${ }^{22} \mathrm{p}$ Values $<0.05$ were considered statistically significant.

\section{RESULTS}

\section{Clinical findings and basic CSF examination results}

At the time of diagnosis, the mean duration of symptoms in NB patients was 11 days (median 7; range 1-40). Only $32.1 \%$ of patients (nine of 28) remembered a tick bite. The most frequent neurological symptoms in NB patients were polyradiculitis (nine of 28) and facial nerve palsy (10 of 28). In CSF, all patients with NB showed a lymphocytic pleocytosis, and most of the patients $(82 \%)$ revealed increased CSF protein measured by an elevation of $\mathrm{Q}_{\mathrm{alb}}$ (table 1). Intrathecal IgM synthesis was found in $78 \%$, while IgG and IgA synthesis were observed in $35.7 \%$ (table 1). All NB patients showed elevated BB-IgG-AI ( $\geq 1.5$ ), with a median AI of 17 (range 2.6-104, table 1).

\section{Assay validation}

ELISA matrix spike recovery was acceptable, with an average recovery of $100 \%$ and a range in spike recoveries of $93-109 \%$

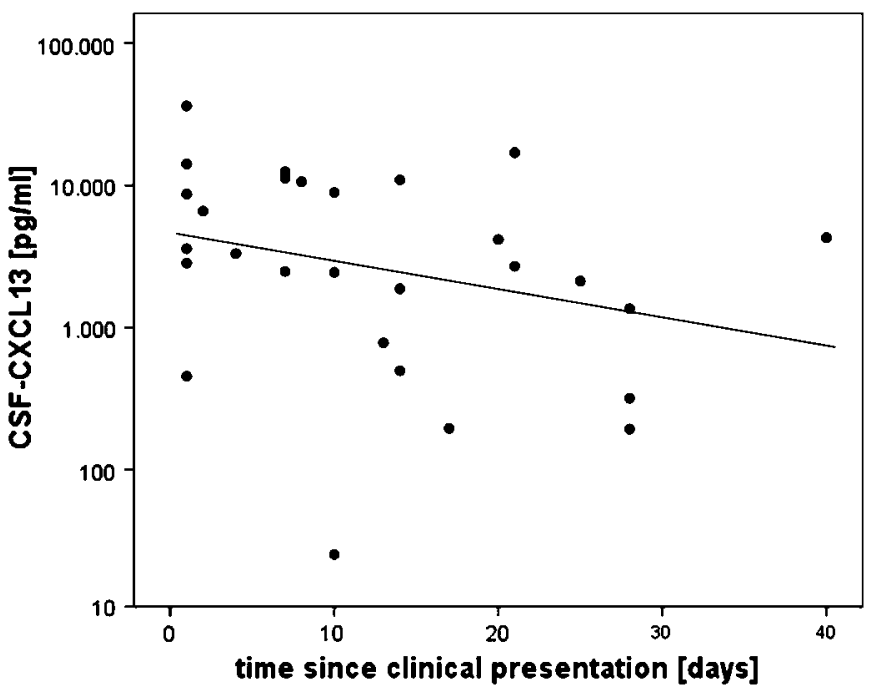

Figure 3 Serum CXCL13 (pg/ml) in bacterial CNS disease (B-CNS-D), neuroborreliosis (NB) and other neurological diseases; Kruskal-Wallis test $\mathrm{p}<0.001$, pairwise comparisons (Mann-Whitney $U$ test) $\mathrm{p}<0.01$; for explanation of abbreviations, see figure 1. $(n=9)$. Linearity-of-dilution experiments showed an average recovery of $102.5 \%$ (range $98-109 ; n=6$ ). According to linearityof-dilution experiments, concentrations $<3.9 \mathrm{pg} / \mathrm{ml}$ were stated as not detectable.

\section{CXCL13 at diagnostic lumbar puncture}

Patients with NB showed significantly elevated CSF CXCL13 levels as compared with all other groups $(p=0.001$, figure 1$)$. NB patients with a shorter duration of disease ( $\leq 8$ days) showed significantly higher CSF-CXCL13 concentrations as compared with patients with a longer duration of disease ( $>8$ days) (pairwise comparison, $\mathrm{p}=0.016$; scatter plot, figure 2). Higher CSF CXCL-13 concentrations in those patients tended to be associated with a higher CSF leucocyte count $(p=0.095)$, though this did not reach statistical significance. CSF-CXCL13 correlated with neither $\mathrm{Q}_{\mathrm{alb}}(\mathrm{R}=0.350, \mathrm{p}=0.068)$ nor serum-CXCL13 $(\mathrm{R}=0.372 \mathrm{p}=0.067)$. CSF CXCL13 levels were slightly elevated in single cases of bacterial or viral CNS infections, with the highest values being detected in patients with neurosyphilis (NS), Staphylococcus aureus meningomyelitis and meningoencephalitis caused by HSV (figure 1). CXCL13 was below the detection limit in most patients with cephalgia, BP, CNP, GBS and patients with SB (figure 1, table 1). Serum-CXCL13 was elevated in BCNS-D (inclusive NS) but was otherwise not significantly different in $\mathrm{NB}$ as compared with controls (figure 3, table 1). Highest serum-CXCL13 was observed in patients with pneumococcal or Haemophilus influenza infections. The mean CXCL13 $\mathrm{CSF} /$ serum ratio in $\mathrm{NB}$ was 81.9, which was significantly higher than in all other groups $(\mathrm{p}<0.001)$.

$\mathrm{ROC}$ analysis was performed to determine cut-off values of CSF-CXCL13 for diagnosis of NB. To distinguish NB from all other groups, the AUROCC was 0.98 (95\% CI 0.953 to 1.004) for

Table 2 Accuracy of cerebrospinal fluid markers for diagnosis of neuroborreliosis

\begin{tabular}{lll}
\hline & Sensitivity & Specificity \\
\hline Basic cerebrospinal fluid findings & 96.4 (82 to 100$)$ & 63.3 (53 to 73) \\
BB-Al & 100 (88 to 100$)$ & 87.1 (70 to 97) \\
BB-Al+BCF & $96.4(82$ to 100$)$ & 90.3 (74 to 98) \\
CXCL13: $>337 \mathrm{ng} / \mathrm{g}$ & 96.4 (82 to 100$)$ & 96.9 (91 to 99$)$ \\
\hline
\end{tabular}

Sensitivity and specificity are shown as a percentage $(95 \% \mathrm{Cl}$ in parentheses). Basic cerebrospinal fluid findings $(\mathrm{BCF})=$ pleocytosis $>4$ cells, intrathecal $\lg M$ synthesis and/or elevation of $\mathrm{O}_{\text {al }}$

$\mathrm{BB}-\mathrm{Al}$ is $\mathrm{Al} \geq 1.5$. 


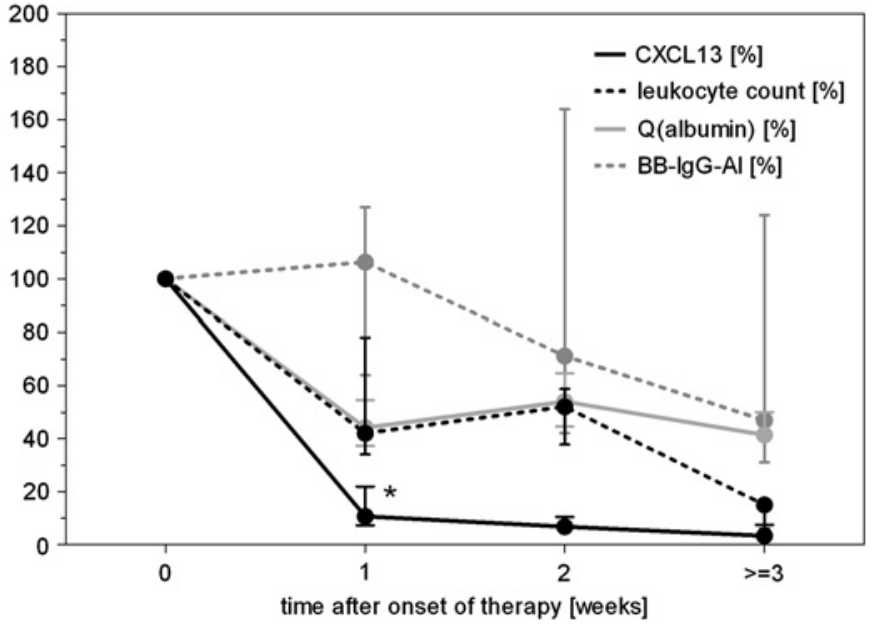

Figure 4 Relative changes (median and IQR) in cerebrospinal fluid CXCL13, leucocyte count, 0 (albumin) (CSF/serum albumin concentration ratio) and (Borrelia burgdorferi immunoglobulin $\mathrm{G}$ antibody index) (BB-lgG-Al) over follow-up in 25 patients with neuroborreliosis.

CSF CXCL13. Using $337 \mathrm{ng} / \mathrm{g}$ as a cut-off, the sensitivity and specificity were found to be 96.4 and $96.9 \%$ (table 2). The diagnostic sensitivity and specificity of BB-IgG-AI were $100 \%$ and $87.1 \%$. Analysis of combined basic CSF variables (pleocytosis, intrathecal synthesis of IgM and/or blood-CSF barrier dysfunction) showed a sensitivity of $96.4 \%$ and a specificity of $63.3 \%$ (table 2). Combination of pathological BB-AI and basic CSF variables yielded a sensitivity of $96.4 \%$ and a specificity of 90.3\% (table 2).

CSF-CXCL13 was elevated (>337 ng/g) in only three cases with inflammatory $\mathrm{CNS}$ reaction not due to $\mathrm{BB}$, including a patient with neurosyphilis, Staphylococcus aureus meningomyelitis and HSV meningoencephalitis. Only in one patient with NB was the CSF CXCL13 below $337 \mathrm{ng} / \mathrm{g}$. BB-IgG-AI was positive $(\geq 1.5)$ in four patients with diagnoses other than NB.

\section{CXCL13 OVER FOLLOW-UP}

Two weeks after onset of antibiotic therapy, $41 \%$ of NB patients showed a complete remission of symptoms, 53\% reported subjective complaints such as pain or paraesthesia, and $6 \%$ showed objective deficits such as persisting Bell's palsy. CXCL13 showed a significant decrease within 1 week $(p=0.008)$ of onset of antibiotic therapy (figure 4), with CSF CXCL13 levels decreasing below the cut-off after 2 weeks. In contrast, the total CSF leucocyte count decreased significantly $(p=0.009)$ only during the second week after onset of antibiotic treatment, though the CSF leucocyte count still remained above the normal level $(>4 / \mu \mathrm{l})$ in all patients. BB-AI showed no significant changes over follow-up $(p=0.356)$. Of all investigated parameters, CXCL13 showed the fastest and most pronounced decrease after onset of antibiotic therapy. In detail, CSF-CXCL13 fell considerably in all $25 \mathrm{NB}$ patients, whereas the CSF leucocyte count (in 28\%), albumin ratio (in 12\%) and total protein (in $20 \%$ ) showed even an increase in some patients.

As control groups, we analysed serial samples from patients with bacterial $(n=11)$ and viral $(n=14)$ meningitis/meningoencephalitis. CSF CXCL13 levels in bacterial infections of the CNS showed no significant change over follow-up $(p=0.112)$, whereas the CSF leucocyte count (in $81 \%$ of patients), albumin ratio (in all) and lactate (in all) decreased. The CSF CXCL13 levels in viral infections of the CNS showed also no significant change during follow-up ( $\mathrm{p}=0.448)$, as did leucocyte count and $\mathrm{Q}_{\mathrm{alb}}$. Serum CXCL13 levels were similar to serum CXCL13 levels of controls.

\section{DISCUSSION \\ CXCL13 as diagnostic marker in neuroborreliosis}

We observed elevated CSF-CXCL13 in NB and neurosyphilis (NS) as compared with other CNS diseases, which is in line with previous studies. ${ }^{18} 2324$ At a cut-off of $337 \mathrm{ng} / \mathrm{g}$, CSF-CXCL13 revealed the highest combined sensitivity (96.4\%) and specificity $(96.9 \%)$ for diagnosis of NB of all parameters investigated. Basic CSF findings had an acceptable sensitivity (96.4\%) but insufficient specificity (63.3\%). Due to our selection criteria of patients with NB, the sensitivity of BB-AI was $100 \%$, but other studies reported BB-AI to be negative in about $10-20 \%$ in the early stages of disease activity (disease duration less than 2-3 weeks). ${ }^{10-14}$ Furthermore, these data revealed the specificity of BB-AI to be comparatively low (87.1\%), which may be due to past infections with $\mathrm{BB}$ or antibody cross-reactivity with other infectious agents such as Treponema pallidum. A combination of BB-AI and basic CSF variables improved diagnostic accuracy in accordance with previous studies ${ }^{10}$ but did not reach the diagnostic accuracy of CXCL13.

Elevated CSF-CXCL13 was observed in only three patients with diagnosis other than NB: one patient was diagnosed as HSV encephalitis, one was diagnosed as neurosyphilis, and one suffered from Staphylococcus aureus meningoencephalitis. We observed no correlation of CSF CXCL13 with either $\mathrm{Q}_{\text {alb }}$ or serum CXCL13, indicating that CSF CXCL13 is mainly synthesised intrathecally.

Serum CXCL13 was not useful for diagnosis of NB but showed elevated levels in patients with B-CNS-D. Consequently, serumCXCL13 could be useful to differentiate between NB and other B-CNS-D, especially in the case of NS, which was also observed to show elevated CSF-CXCL13 concentrations. ${ }^{24}$ The pathophysiological mechanisms underlying this discrepancy of CSF and serum CXCL13 in NB are a matter of speculation. Immune evasion strategies of $\mathrm{BB}$ in the blood compartment such as the downregulation of outer surface proteins (Osp), hiding in extracellular matrix or the secretion of complement-neutralising proteins was suggested to reduce the immune response to $\mathrm{BB}$ in the peripheral blood and consequently the production of CXCL13 by monocytes and dendritic cells. ${ }^{25}$ Furthermore, migration of $\mathrm{BB}$ into the CNS along peripheral nerves could also enable $\mathrm{BB}$ to avoid the host immune system, resulting in low serum CXCL13 levels. ${ }^{2526}$ In the nervous system, OspA has been observed to be upregulated again, inducing the secretion of CXCL13 by interaction with the toll-like receptor 2 of monocytes. ${ }^{25}$

\section{CXCL13 as a marker of disease activity and duration}

Of all the parameters investigated, CSF CXCL13 showed the fastest response to antibiotic therapy with intravenous ceftriaxone, decreasing significantly within 1 week (figure 4). In contrast, BB-AI showed no significant decrease under therapy, which is in line with previous studies that found BB-AI to persist up to several years after acute NB. ${ }^{10-14}$ Accordingly, BBAI could mimic acute inflammation with $\mathrm{BB}$, especially in cases of elevated cell count due to an infection with another pathogen. The fast decline under therapy with ceftriaxone suggests that CSF CXCL13 may offer a new tool to measure disease activity in patients with NB. This is in line with a previous study that reported a strong correlation between CXCL13 gene expression and spirochetal load. ${ }^{27}$ However, we also observed high levels of CSF CXCL13 to be related to a short duration of disease prior to lumbar puncture, suggesting that CSF CXCL13 may be a marker 
of disease duration in NB rather than a marker of disease activity. Future studies including a larger number of patients with follow-up data will have to clarify whether CXCL13 is a marker of disease activity or merely a marker of disease duration in NB.

\section{CONCLUSION}

Our study confirms the relevance of CXCL13 as a diagnostic biomarker of NB. It suggests that CSF CXCL13 levels in NB are linked to duration of disease and could be a marker of disease activity and response to antibiotic therapy. We recommend CSFCXCL13 to be used for diagnosis of NB in addition to established parameters such as BB-AI. Especially in cases with positive BBAI due to past $\mathrm{NB}$ and elevated CSF leucocyte count due to an infection with another pathogen, CSF-CXCL13 is currently the best tool to differentiate between active and past infection with BB.

Acknowledgements We thank V Lehmensiek and H Mogel for their technical assistance.

\section{Competing interests None}

Ethics approval Ethics approval was provided by the Ethics committee, University of Ulm.

Contributors MS, HT, HWP and TAR were involved in the conception and design of the study. Data were acquired by MS, TAR and HWP. The first draft of the manuscript was designed by MS and JB. It was critically revised by HT, ACL, TAR and HWP. The final version for submission was approved by all coauthors.

Provenance and peer review Not commissioned; externally peer reviewed.

\section{REFERENCES}

1. Burgdorfer W, Barbour AG, Hayes SF, et al. Lyme disease-a tick-borne spirochetosis? Science 1982;216:1317-19.

2. Benach JL, Bosler EM, Hanrahan JP, et al. Spirochetes isolated from the blood of two patients with Lyme disease. N Engl J Med 1983;308:740-2.

3. Steere AC, Grodzicki RL, Kornblatt AN, et al. The spirochetal etiology of Lyme disease. N Engl J Med 1983;308:733-40.

4. Pachner AR, Steere AC. The triad of neurologic manifestations of Lyme disease: meningitis, cranial neuritis, and radiculoneuritis. Neurology 1985;35:47-53.

5. Pfister HW, Wilske B, Weber K. Lyme borreliosis: basic science and clinical aspects. Lancet 1994;343:1013-16.
6. Hengge UR, Tannapfel A, Tyring SK, et al. Lyme borreliosis. Lancet Infect Dis 2003;3:489-500

7. Kaiser R. Neuroborreliosis. J Neurol 1998;245:247-55.

8. Reiber H, Lange P. Quantification of virus-specific antibodies in cerebrospinal fluid and serum sensitive and specific detection of antibody synthesis in brain. Clin Chem 1991;37:1153-60.

9. Felgenhauer $\mathbf{K}$, Reiber $\mathrm{H}$. The diagnostic significance of antibody specificity indices in multiple sclerosis and herpes virus induced diseases of the nervous system. Clin Investig 1992; 70:28-37.

10. Tumani H, Nolker G, Reiber H. Relevance of cerebrospinal fluid variables for early diagnosis of neuroborreliosis. Neurology 1995;45:1663-70.

11. Kaiser R, Rauer S. Analysis of the intrathecal immune response in neuroborreliosis to a sonicate antigen and three recombinant antigens of Borrelia burgdorferi sensu stricto. Eur J Clin Microbiol Infect Dis 1998;17:159-66.

12. Hansen $\mathbf{K}$, Lebech AM. Lyme neuroborreliosis: a new sensitive diagnostic assay for intrathecal synthesis of Borrelia burgdorferi-specific immunoglobulin $G, A$, and $M$. Ann Neurol 1991:30:197-205.

13. Wilske B, Bader L, Pfister HW, et al. Diagnosis of Lyme neuroborreliosis. Detection of intrathecal antibody formation. Fortschr Med 1991;109:441-6.

14. Hammers-Berggren S, Hansen K, Lebech AM, et al. Borrelia burgdorferi-specific intrathecal antibody production in neuroborreliosis: a follow-up study. Neurology 1993:43:169-75

15. Hansen K, Cruz M, Link H. Oligoclonal Borrelia burgdorferi-specific IgG antibodies in cerebrospinal fluid in Lyme neuroborreliosis. J Infect Dis 1990;161:1194-202.

16. Stiernstedt GT, Granstrom M, Hederstedt B, et al. Diagnosis of spirochetal meningitis by enzyme-linked immunosorbent assay and indirect immunofluorescence assay in serum and cerebrospinal fluid. J Clin Microbiol 1985;21:819-25.

17. Rupprecht TA, Pfister HW, Angele B, et al. The chemokine CXCL13 (BLC): a putative diagnostic marker for neuroborreliosis. Neurology 2005;65:448-50.

18. Ljostad U, Mygland A. CSF B-lymphocyte chemoattractant (CXCL13) in the early diagnosis of acute Lyme neuroborreliosis. J Neurol 2008;255:732-7.

19. Nelson PJ, Krensky AM. Chemokines, chemokine receptors, and allograft rejection. Immunity 2001;14:377-86.

20. Sussmuth SD, Tumani $\mathrm{H}$, Ecker D, et al. Amyotrophic lateral sclerosis: disease stage related changes of tau protein and S100 beta in cerebrospinal fluid and creatine kinase in serum. Neurosci Lett 2003;353:57-60.

21. Reiber H. Cerebrospinal fluid-physiology, analysis and interpretation of protein patterns for diagnosis of neurological diseases. Mult Scler 1998;4:99-107.

22. Youden WJ. Index for rating diagnostic tests. Cancer 1950:3:32-5.

23. Rupprecht TA, Koedel U, Angele B, et al. Cytokine CXCL13-a possible early CSF marker for neuroborreliosis. Nervenarzt 2006;77:470-3

24. Rupprecht TA, Kirschning CJ, Popp B, et al. Borrelia garinii induces CXCL13 production in human monocytes through Toll-like receptor 2. Infect Immun 2007;75:4351-6.

25. Rupprecht TA, Koedel U, Fingerle V, et al. The pathogenesis of lyme neuroborreliosis: from infection to inflammation. Mol Med 2008;14:205-12.

26. Horstrup P, Ackermann R. Tick born meningopolyneuritis (Garin-Bujadoux, Bannwarth) [author's transl]. Fortschr Neurol Psychiatr Grenzgeb 1973:41:583-606.

27. Narayan K, Dail D, Li L, et al. The nervous system as ectopic germinal center: CXCL13 and IgG in lyme neuroborreliosis. Ann Neurol 2005:57:813-23. 
Received 22 December 2008

Revised 28 July 2009

Accepted 25 August 2009

Published Online First 14 June 2010

J Neurol Neurosurg Psychiatry 2010;81:1175-1177. doi:10.1136/jnnp.2008.171116

\section{REFERENCES}

1. Bedwell SF. Some observations on hemiballismus. Neurology 1960;10:619-22.

2. Schwarz GA, Barrows LJ. Hemiballism without involvement of Luys' body. Arch Neurol 1960;2:420-34.

3. Yahikozawa $\mathbf{H}$, Hanyu N, Yamamoto $\mathrm{K}$, et al. Hemiballism with striatal hyperintensity on T1 weighted MRI in diabetic patients: a unique syndrome. J Neurol Sci 1994;124:208-14.

4. Postuma R, Lang AE. Hemiballism: revisiting a classic disorder. Lancet Neurol 2003;2:661-8

5. Lee EJ, Park JH, Ihn YK, et al. Acute bilateral basal ganglia lesions in diabetic uraemia: diffusion-weighted MRI. Neuroradiology 2007; 49:1009-13.

6. Ahlskog JE, Nishino $\mathrm{H}$, Evidente VGH, et al. Persistent chorea triggered by hyperglycemic crisis in diabetes. Mov Disord 2001;16 890-8.

7. Shan DE, Pan HC, Ho DMT, et al. Presence of activated microglia in a high-signal lesion on T1 weighted MR images: a biopsy sample re-examined. Am J Neuroradiol 2007;28:602.

8. Aoe H, Takeda $\mathrm{Y}$, Kawahara $\mathrm{H}$, et al. Clinical significance of $\mathrm{T} 1$ weighted images following transient cerebral ischemia. J Neurol Sci 2006;15:19-24.

9. Kim HJ, Moon WJ, Oh J, et al. Subthalamic lesion on MR imaging in a patient with nonketotic hyperglycemia-induced hemiballism. Am J Neuroradiol 2008;29:526-7.

10. Streit WJ. Microglia and neuroprotection: implications for Alzheimer's disease. Brain Res Rev 2005:48:234-9.

\section{CORRECTIONS}

doi:10.1136/jnnp.2009.195438corr1

M Senel, T A Rupprecht, H Tumani, et al. The chemokine CXCL13 in acute neuroborreliosis (J Neurol Neurosurg Psychiatry 2010;81:929-933). Figures 1, 2 and 3 were inadvertently swapped around during the production process. JNNP would like to apologise to the authors for this error. The correct order and legends are as follows:

In the Results, under the heading CXCL13 at diagnostic lumbar puncture it should read: "Patients with NB showed significantly elevated CSF CXCL13 levels as compared with all other groups $(p<0.001$, figure 1$)$. NB patients with a shorter duration of disease ( $\leq 8$ days) showed significantly higher CSFCXCL13 concentrations as compared with patients with a longer duration of disease ( $>8$ days) (pairwise comparison, $\mathrm{p}=0.016$ scatter plot, figure 3). Higher CSF CXCL-13 concentrations in those patients tended to be

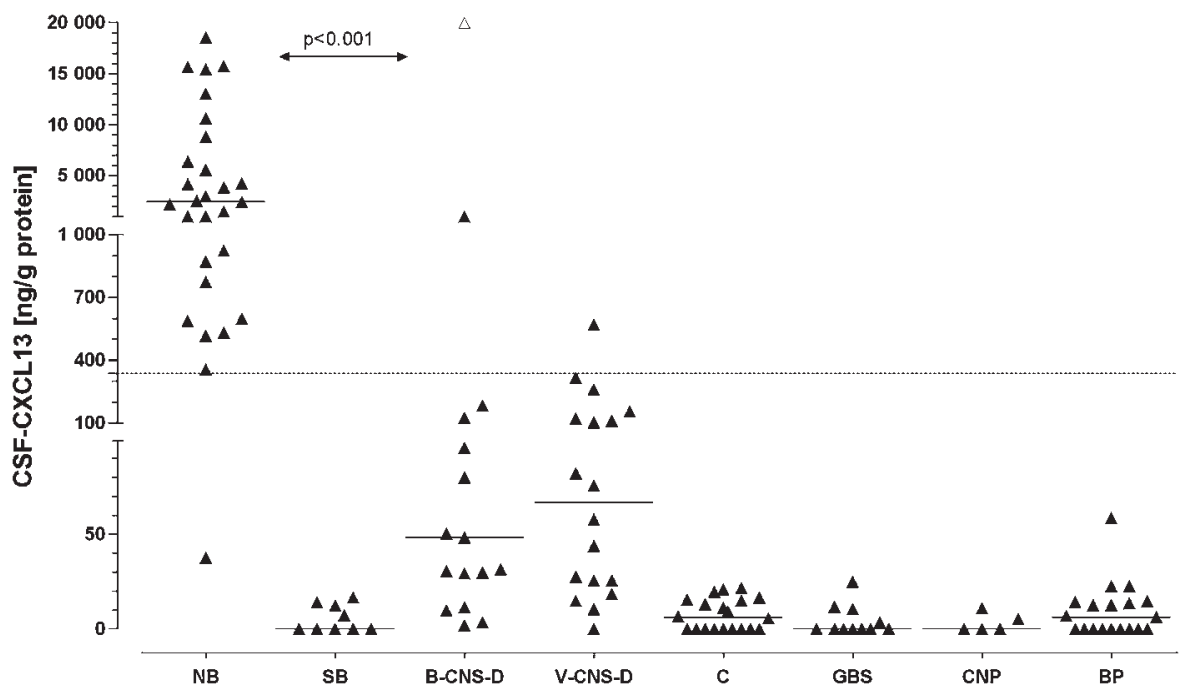

Figure 1 CXCL13 (ng/g protein) in the cerebrospinal fluid (CSF) of neuroborreliosis and other neurological diseases; horizontal solid lines indicate medians. Kruskal-Wallis test and pairwise comparisons (Mann-Whitney $U$ test) revealed a significant difference between the groups $(p<0.001)$. The dashed line at $337 \mathrm{ng} / \mathrm{g}$ represents the cut-off level yielding the highest combined sensitivity and specificity for discriminating patients with NB from those with other diseases. A grey triangle indicates an outlier (neurosyphilis patient) with cerebrospinal fluid CXCL13 of 113000 $\mathrm{ng} / \mathrm{g}$. The $\mathrm{y}$-axis is broken twice. B-CNS-D, bacterial CNS disease; BP, Bell's palsy; C, cephalgia; CNP, cranial nerve palsies; GBS, Guillain-Barré syndrome; NB, definite neuroborreliosis; SB, systemic borreliosis; V-CNS-D, viral CNS disease.

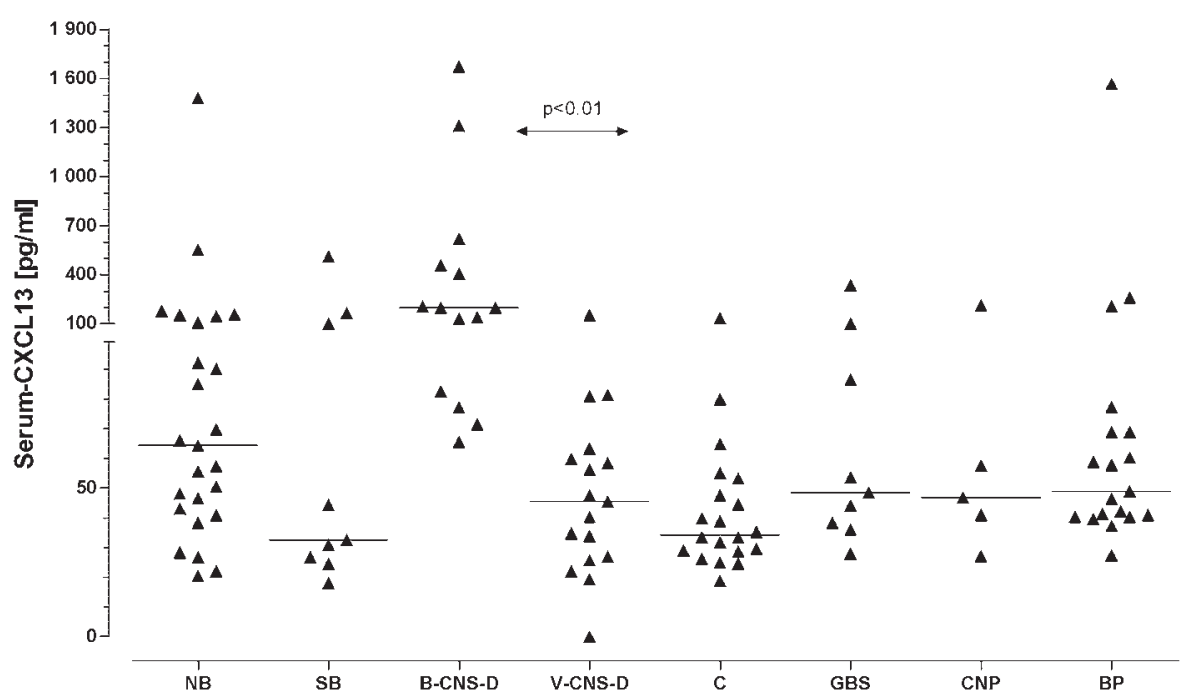

Figure 2 Serum CXCL13 (pg/ml) in bacterial CNS disease (B-CNS-D), neuroborreliosis (NB) and other neurological diseases; Kruskal-Wallis test $p<0.001$, pairwise comparisons (Mann-Whitney U test) $\mathrm{p}<0.01$.

associated with a higher CSF leucocyte count $(p=0.095)$, though this did not reach statistical significance. CSF-CXCL13 correlated with neither Qalb $(\mathrm{R}=0.350$, $\mathrm{p}=0.068)$ nor serum-CXCL13 $(\mathrm{R}=0.372$ $\mathrm{p}=0.067)$. CSF CXCL13 levels were slightly elevated in single cases of bacterial or viral CNS infections, with the highest values being detected in patients with neurosyphilis (NS), Staphylococcus aureus meningomyelitis and meningoencephalitis caused by HSV (figure 1). CXCL13 was below the detection limit in most patients with cephalgia, BP, CNP, GBS and patients with SB (figure 1, table 1). Serum-CXCL13 was elevated in B-CNS-D (inclusive NS) but was otherwise not significantly different in $\mathrm{NB}$ as compared with controls (figure 2, table 1). Highest serum-CXCL13 was observed in patients with pneumococcal or Haemophilus influenza infections. The mean CXCL13 CSF/ serum ratio in NB was 81.9, which was significantly higher than in all other groups $(\mathrm{p}<0.001)$. 


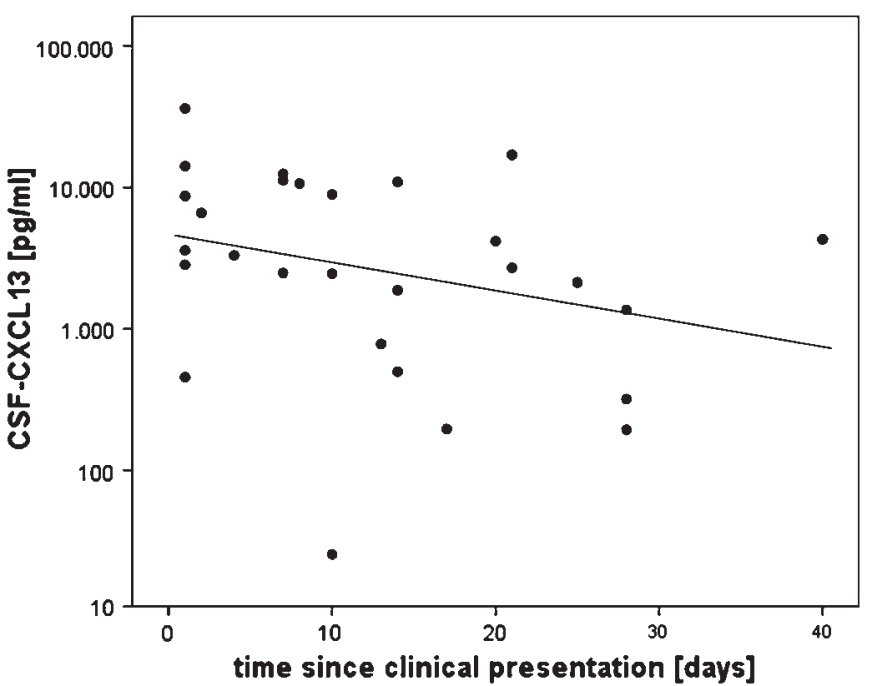

Figure 3 Cerebrospinal fluid CXCL13 in neuroborreliosis patients prior to therapy plotted against time since the onset of symptoms (time to lumbar puncture). The straight line is a regression line; the correlation was significant $(p=0.044, R=-0.383)$.

\section{doi:10.1136/jnnp.2009.173732corr1}

K Brantberg. Paroxysmal staccato tinnitus: a carbamazepine responsive hyperactivity dysfunction symptom of the eighth cranial nerve J Neurol Neurosurg Psychiatry 2010;81: 451-455. A number of errors in the author's manuscript were published uncorrected by JNNP. In the first sentence of the introduction "N VII" should have been deleted. In the same section, fourth paragraph, second to last sentence it should be "fifth and seventh cranial nerves" rather than "fifth and eigth cranial nerves". In the Discussion, in both the second and fourth paragraph it refers to the fifth and seventh cranial nerves when it should have been the seventh and eigth cranial nerves. JNNP would like to apologise for not correcting these errors which occurred during editing and which were also pointed out by the author before publication.

doi:10.1136/jnnp.2009.178863corr1

D Wade. Measuring case complexity in neurological rehabilitation. $J$ Neurol Neurosurg Psychiatry 2010;81:127. The commentary by Derick Wade contained several errors that need correction.

Column 1, paragraph 2: The RCS has four components (not three).

Column 2, paragraphs 1 and 2: The RCS can be completed after a single assessment, and does not require two weeks as an inpatient. It can be completed either prospectively to record rehabilitation 'needs' or retrospectively to describe the level of interventions actually provided. In the analysis reported by Turner-Stokes et al (J Neurol Neurosurg Psychiatry 2010;81: 146-153), it was used retrospectively. Professor Wade therefore wishes to withdraw the statement in paragraph 2: "There are two other reasons for being concerned about this scale. The first is practical. It cannot help determine 'complexity' before patients are admitted, yet this is the primary need of most services, and most data are subjective, which reduces its credibility with purchasers."

Column 3, last paragraph should be amended to read: "Nonetheless, the Rehabilitation Complexity Scale is a simple, clinical measure of overall resource use. Provided its limitations are recognised, it may prove useful."

In addition, Professor Wade overlooked a potential competing interest; although he was not directly involved in the analysis by Turner-Stokes et al (pp 146-153), he is a member of the same academic department (Department of Palliative Care Policy and Rehabilitation, Kings College, London). He is also a co-investigator in the NIHR-funded Programme under which the RCS and other tools to address complexity of rehabilitation needs and interventions are being developed.

In writing this commentary, Professor Wade sought to highlight some of the limitations of a tool that is necessarily simplified for practical utility and to place it in the context of the broader issues involved in assessing case complexity in rehabilitation, which are also being addressed in other sections of the programme. His critical appraisal of the RCS and failure to declare his association should not be taken in any sense to imply disengagement from the programme. He remains fully committed to this important area of work. 


\section{JNNP}

\section{The chemokine CXCL13 in acute neuroborreliosis}

Makbule Senel, Tobias A Rupprecht, Hayrettin Tumani, et al.

J Neurol Neurosurg Psychiatry 2010 81: 929-933 originally published online December 3, 2009

doi: 10.1136/jnnp.2009.195438

Updated information and services can be found at:

http://jnnp.bmj.com/content/81/8/929.full.html

These include:

References This article cites 27 articles, 10 of which can be accessed free at: http://jnnp.bmj.com/content/81/8/929.full.html\#ref-list-1

Article cited in:

http://jnnp.bmj.com/content/81/8/929.full.htmI\#related-urls

Email alerting

Receive free email alerts when new articles cite this article. Sign up in

the box at the top right corner of the online article.

service

Topic Articles on similar topics can be found in the following collections

Collections

Immunology (including allergy) (1595 articles)

Infection (neurology) (424 articles)

Cranial nerves (458 articles)

Headache (including migraine) (370 articles)

Pain (neurology) (631 articles)

Notes

To request permissions go to:

http://group.bmj.com/group/rights-licensing/permissions

To order reprints go to:

http://journals.bmj.com/cgi/reprintform

To subscribe to BMJ go to:

http://group.bmj.com/subscribe/ 